\title{
A stochastic optimization approach for paper recycling reverse logistics network design under uncertainty
}

\author{
*S. Soner Kara; S. Onut \\ Department of Industrial Engineering, Faculty of Mechanic, Yildiz Technical University, 34349, Istanbul, Turkey \\ Received 11 February 2010; $\quad$ revised 17 May 2010; accepted 26 July 2010; $\quad$ available online 1 September 2010
}

\begin{abstract}
One of the most important objectives of a manufacturing firm is the efficient design and operation of its supply chain to maximize profit. Paper is an example of a valuable material that can be recycled and recovered. Uncertainty is one of the characteristics of the real world. The methods that cope with uncertainty help researchers get realistic results. In this study, a two-stage stochastic programing model is proposed to determine a long term strategy including optimal facility locations and optimal flow amounts for large scale reverse supply chain network design problem under uncertainty. This network design problem includes optimal recycling and collection center locations and optimal flow amounts between the nodes in the multi-facility environment. Proposed model is suitable for recycling/ manufacturing type of systems in reverse supply chain. All deterministic, stochastic models are mixed-integer programing models and are solved by commercial software GAMS 21.6/CPLEX 9.0.
\end{abstract}

Keywords: Network optimization; Recycling; Two-Stage Stochastic programming

\section{INTRODUCTION}

In the past decade, rapid developments in technology, the emergence of new industrial products and shortened product life cycles have resulted in an increasing number of discarded products and caused growing environmental problems in the developed world. The current threatening level of environmental problems, along with related customer pressure and governmental regulations, motivates corporations to undertake environmentally-conscious initiatives (Tuzkaya and Gülsün, 2008; Lin et al., 2010). Due to the governmental regulations and consumer concerns regarding these environmental issues, an increasing number of companies have focused on reduction efforts in the amount of waste stream, diversion of the discarded products from landfills and disposition of the retired products properly. Increasing environmental problems enforce companies to be more environmental responsible (Tuzkaya et al., 2009). To facilitate the reverse flow of used products from consumers to manufacturers in an efficient manner, the most appropriate approach is to create a reverse supply chain network (Chien and Shih, 2007). Regarding the reverse supply chain networks for product recovery,

\footnotetext{
\4Corresponding Author Email: ssoner@yildiz.edu.tr
} Tel./Fax:+90 2123832902 reverse supply chain can be described as the process of collecting used products from the consumers to the manufacturers for the purpose of capturing value or appropriate disposal activities (Abdel-Ghani and Elchaghaby, 2007; Abdel-Ghani et al., 2009). These activities may include repairing of warranty returns, remanufacturing of the manufacturing of the same products, reselling of the products in good conditions and reusing of end-of-use returns.

Reverse supply chain network design is a strategic issue of primary importance for the economic viability of product recovery activities. Design and implementation of reverse supply chain require setting up an appropriate network infrastructure for the increasing flows of used and recovered products (Jalili Ghazi Zade and Noori, 2008; Panjeshahi and Ataei, 2008). The reverse flow of the product originates from several points and is consolidated at just a few (or one) destinations. General network structure, most appropriate physical locations, the number of echelons, the number of facilities required, their capacities, the type of necessary facilities and transportation links between the network elements need to be determined to convey used products from their former users to a producer and to future markets again. Furthermore the 
markets for recovered products have to be identified (Listeş, 2007). A number of modeling tools and techniques have been mentioned in the literature for designing reverse supply chain networks (Bandyopadhayay and Chaltopadhayay, 2007; Chowdhury and Rahman, 2008). Most of the existing models have been developed through conventional mathematical programming techniques (Farzaneh and Saboohi, 2007). Some related studies for reverse supply chain network design utilizing these techniques can be summarized in Table 1.

\section{MATERIALS AND METHODS}

Two-stage stochastic programming

The set of decisions is divided into two groups in two-stage stochastic programming:

- A number of decisions have to be taken before the experiment. All these decisions are called as the firststage decisions and the period, in which these decisions are taken, is called as the first stage.

- A number of decisions have to be taken after the experiment. These are called as the second-stage decisions. The corresponding period is called as the second stage.

The first-stage decisions are represented by the vector $x$, while the second-stage decisions are represented by the vector $y$ or $y(\omega)$ or even $y(\omega, x)$ and $\xi(\omega)$ is the random event. The sequence of events and decisions is thus summarized as $x \rightarrow \xi(\omega) \rightarrow y(\omega, x)$. The definitions of the first and the second stages are only related to before and after the random experiment and may in fact contain sequences of decisions and events. The general model is as follows (Birge and Louveaux , 1997):

$\min z=c^{T} x+E \xi\left[\min q(\omega)^{T} y(w)\right]$

s.t

$A x=b$

$T(\omega) x+W y(\omega)=h(\omega)$

$x \geq 0, y(\omega) \geq 0$

\section{Case study}

As a real world case study, paper recycling network problem is proposed to verify the model. This case study is a proposal for a newly installing firm which has an objective to recyle 280,000 tons of waste paper. One ton waste paper recycling prevents; cutting 17 big trees, using $4100 \mathrm{kw} / \mathrm{h}$ energy, spending 25,900 lt water and leaving 30 kilos hazardous gas into the air.
Besides waste paper is the easiest reusable material in packing materials. Waste paper can be recycled between one to twelve times.

Network design models try to determine suitable facilities, the optimal locations and capacities of facilities and flow of amounts between nodes of network considering cost factor. This study considers the design of single-product, two-echelon, capacitated reverse network.

\section{Network characteristics}

Two types of facilities are considered in the study:

1) Collection center: Collected waste paper is transferred from customers to collection centers. Mixed waste paper is sorted, pressed and baled. In the sorting process some products in bad condition are sorted in a longer time. For these kinds of products, the model decides to send them to waste center or to sort them in a longer time.

2) Recycling center: Some waste paper which is not sent to a collection center is directly transferred to recycling center. Same processes are carried out for sorting process. In the sorting process some products in bad condition are sorted in a longer time. For these kinds of products the model decides to send them to waste center or to sort them in a longer time. In this way, raw material is gained after recycling process. Also new raw materials are used to manufacture new products to satisfy customers' demand.

Hence, in recycling center; manufacturing, recycling and sorting processes can be put into practice; on the other hand, in collection center only sorting process can be put into practice. Each collection center and recycling center can be supplied by more than one node.

Also there are existing sites in the model. Customers and waste center are the existing sites in the network. Customers are grouped in zones. Each customer zone has a demand that must be satisfied. Moreover, used waste paper is collected from customers for recycling. There are two strategies for recycling of used products: The first one is regional strategy. The idea is to transport collected waste paper to collection center. In sorting activity, better conditioned products are transported to recycling center, while products in bad condition are evaluated according to the cost factor. Some of them are sorted in a longer time and then transported to recycling center or to waste center. The 
Int. J. Environ. Sci. Tech., 7 (4), 717-730, Autumn 2010

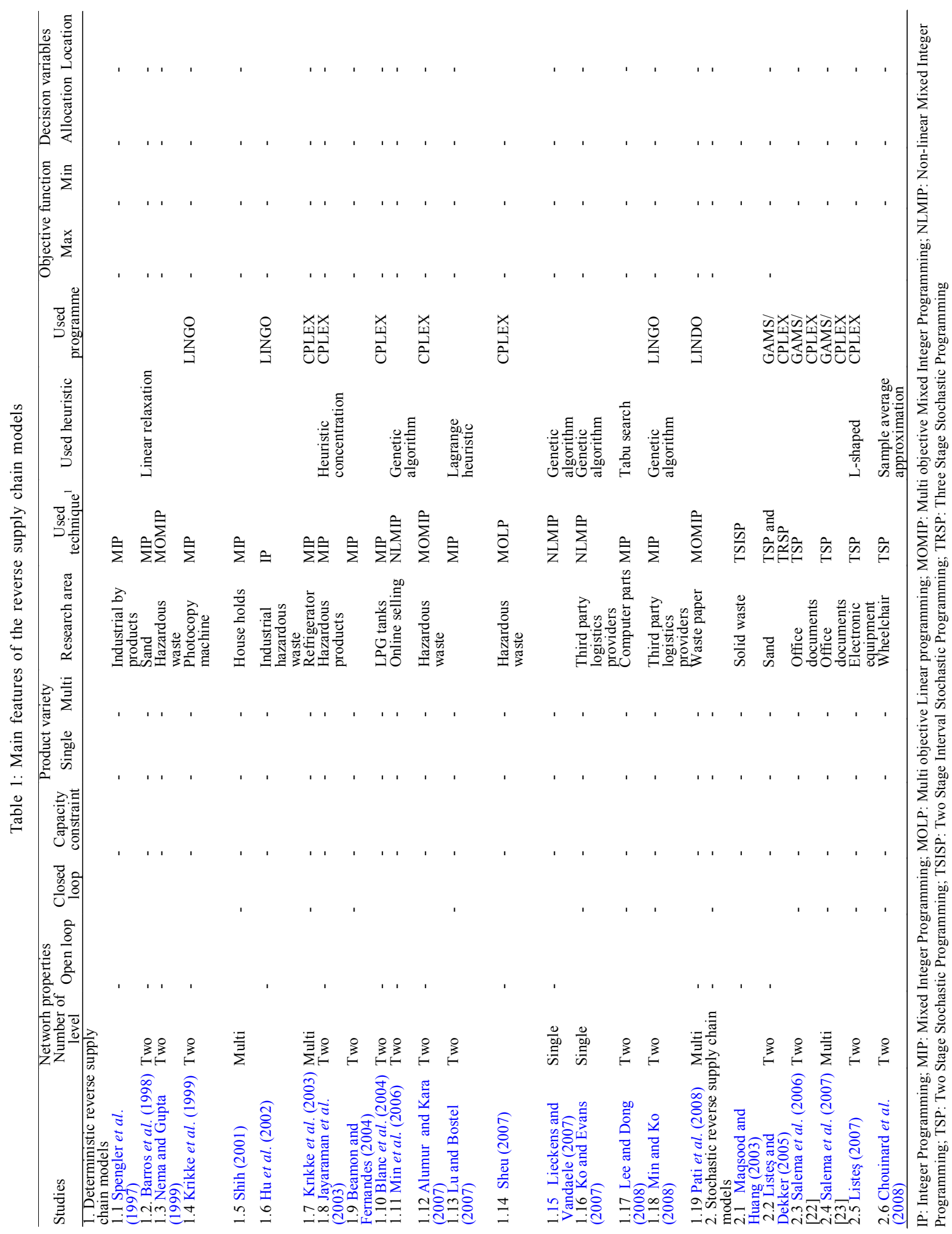


second one is central strategy. The idea is to directly transport used products to recycling center and to do all the same sorting and recycling activities in this center. Both two strategies are integrated in the model. A customer may be served by more than one collection center and recycling center. Demand and the number of reused products that can be collected from customers are assumed as uncertain. Therefore, in the stochastic model these two parameters are represented by scenarios.

The following assumptions are accepted in the model:

- Products that are produced from new raw materials and products that are produced from recycled raw materials are sold at the same price in the market.

- There is a fixed cost for opening collection and recycling center. For this reason, there is a limitation for the number of collection centers and recycling centers that can be opened, but which collection center and recycling center can be opened is decided by the model. The maximum number for the collection center is three, whereas the minimum number is one. For recycling center, only one center is allowed. This constraint is included in the model because of the fact that it avoids budget excess.

- Because of the fact that there is not any recycling legislation in Turkey, in this problem the quantity of the paper which will be collected from the customers is determined by the proposed model. The percentage of uncollected products is assumed as certain, but the model decides the amount of uncollected products considering penalty cost.

- The percentages of products in bad condition in collection and recycling centers are assumed as certain, but the model decides the amount of products that can be sorted considering higher sorting cost.

- Transportation cost is determined per ton and per kilometer and total transportation costs in the objective function are obtained by multiplying these costs with distances between two nodes. These distances are calculated by Euclidian principle.

- The number of customers that waste paper is collected from is not the same as the number of customers that are served. There are fifty customers that waste paper is collected from and thirty customers that are served.

- The capacity of recycling center is partitioned for products that are produced from new raw materials and products that are produced from recycled raw materials. The percentage of capacity utilization for two activities is assumed as certain. Problem dimensions are as follows:

50 customers are involved in the problem and 17 collection centers and 17 recycling centers are evaluated for selection. Model is designed for single product. The conceptual framework of the problem addressed in this study is depicted in Fig. 1.

A feature of network design problem is that the network must be able to meet the amount of products coming from customers. However, it is difficult to predict the amount of collected products. This is generally uncertain. Likewise customer demand is generally uncertain. It is appropriate to disclose uncertainty by expressing it with scenarios. Forty scenarios are generated for demand and the amount of products that can be collected from customers individually. These parameters are assumed to fit to normal distribution. Last year's data is obtained and assumed as mean values for normal distribution. $2.5 \%$ of mean values is used as variance. Table 2 summarizes these parameters' distributions in scenarios. Forty random numbers are generated and forty scenario values for these two parameters are calculated. Also all scenario probabilities are assumed as same in order not to emphasize any of the scenarios.

In two-stage stochastic programming, as mentioned in the second section, decisions can be made before and after uncertainty is disclosed. The problem is how to efficiently locate collection centers and recycling center and how to allocate flows to gain maximum revenue under uncertainty. In this study, the first stage decisions correspond to the location decisions that must be made for opening facilities before the values of the random parameters become known and the second stage decisions correspond to the flow amount decisions through the established network after the values of the random parameters become known. Consequently, the location variables $x$ are assigned as the first stage variables and the allocation variables $y$ are assigned as the second stage variables. In this way, value of $x$ is fixed in the first stage, the second stage decisions depend on scenarios and hence variables $y$ change under different realizations of $\omega$. Fig. 2 represents the three phases of the model.

First phase is the preliminary research phase. In this phase, the related problem is defined, studies in literature are investigated and expert arguments are 


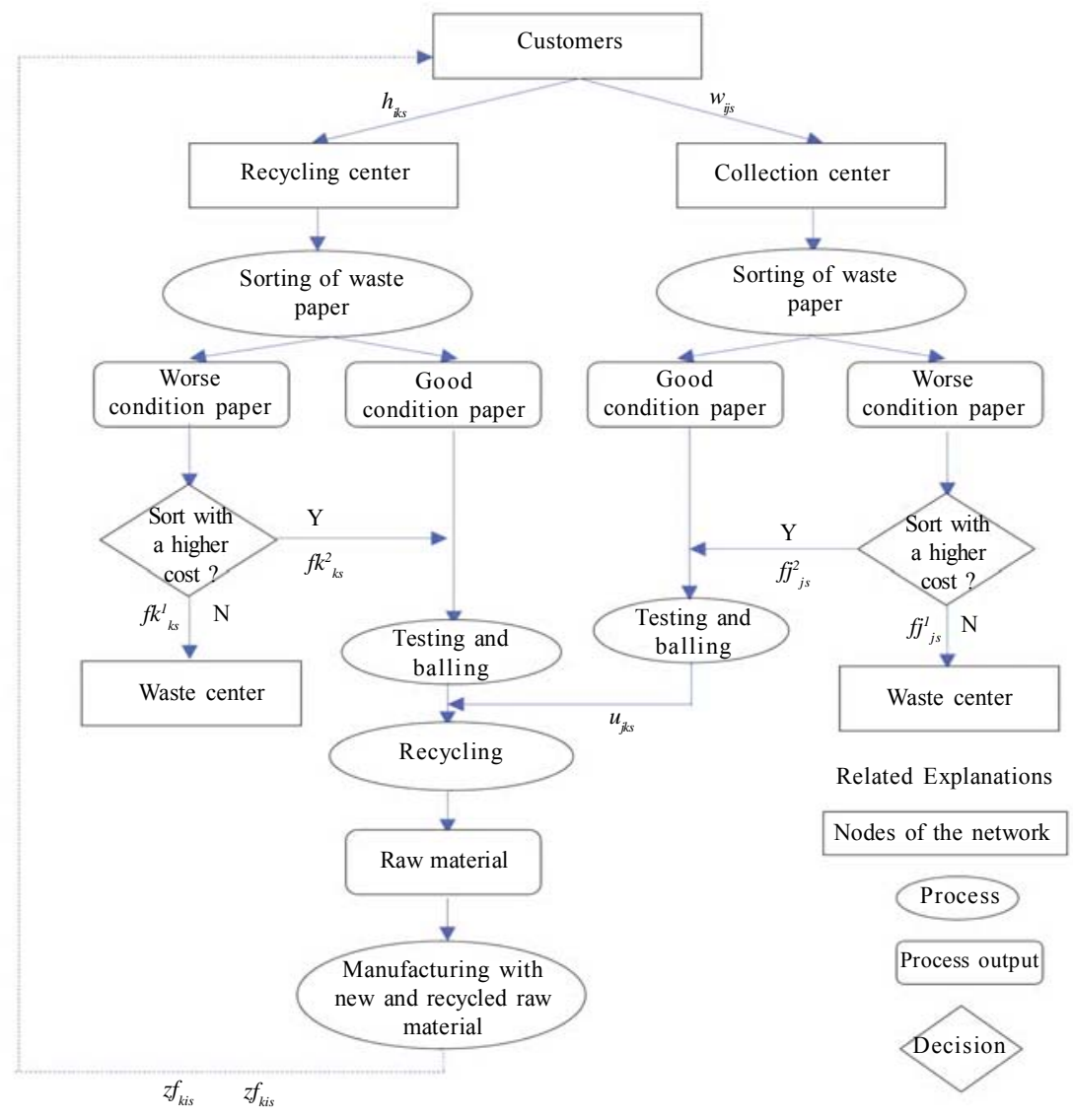

Fig. 1: The conceptual framework of the problem

Table 2: Demand and return distributions

\begin{tabular}{lccccccr}
\hline \multicolumn{7}{c}{ Demand and return distributions $\sim N\left(\mu, \sigma^{2}\right)$} \\
\hline Customer & Demand & Return & Customer & Demand & Return & Customer Demand & Return \\
\hline 1 & $\sim N(18000,7200)$ & $\sim N(8000,3200)$ & 21 & $\sim N(56000,22400)$ & $\sim N(5600,2240)$ & 41 & $\sim N(5420,2168)$ \\
2 & $\sim N(9200,3680)$ & $\sim N(6560,2624)$ & 22 & $\sim N(12000,4800)$ & $\sim N(3400,1360)$ & 42 & $\sim N(7800,3120)$ \\
3 & $\sim N(16500,6600)$ & $\sim N(7800,3120)$ & 23 & $\sim N(23000,9200)$ & $\sim N(11200,4480)$ & 43 & $\sim N(14500,5800)$ \\
4 & $\sim N(8900,3560)$ & $\sim N(3200,1280)$ & 24 & $\sim N(15600,6240)$ & $\sim N(6700,2680)$ & 44 & $\sim N(2300,920)$ \\
5 & $\sim N(4500,1800)$ & $\sim N(4500,1800)$ & 25 & $\sim N(10600,4240)$ & $\sim N(8900,3560)$ & 45 & $\sim N(1230,492)$ \\
6 & $\sim N(12000,4800)$ & $\sim N(1200,480)$ & 26 & $\sim N(9000,3600)$ & $\sim N(4500,1800)$ & 46 & $\sim N(3400,1360)$ \\
7 & $\sim N(12000,4800)$ & $\sim N(5300,2120)$ & 27 & $\sim N(8700,3480)$ & $\sim N(5600,2240)$ & 47 & $\sim N(4500,1800)$ \\
8 & $\sim N(13000,5200)$ & $\sim N(6200,2480)$ & 28 & $\sim N(17000,6800)$ & $\sim N(12300,4920)$ & 48 & $\sim N(8900,3560)$ \\
9 & $\sim N(7000,2800)$ & $\sim N(3000,1200)$ & 29 & $\sim N(16000,6400)$ & $\sim N(12000,4800)$ & 49 & $\sim N(5600,2240)$ \\
10 & $\sim N(34000,13600)$ & $\sim N(3900,1560)$ & 30 & $\sim N(9800,3920)$ & $\sim N(3840,1536)$ & 50 & $\sim N(4590,1836)$ \\
11 & $\sim N(5000,2000)$ & $\sim N(3000,1200)$ & 31 & & $\sim N(4500,1800)$ & & \\
12 & $\sim N(12000,4800)$ & $\sim N(4370,1748)$ & 32 & & $\sim N(6800,2720)$ & & \\
13 & $\sim N(32000,12800)$ & $\sim N(4900,1960)$ & 33 & & $\sim N(4590,1836)$ & & \\
14 & $\sim N(14000,5600)$ & $\sim N(9500,3800)$ & 34 & & $\sim N(1200,480)$ & & \\
15 & $\sim N(12000,4800)$ & $\sim N(890,356)$ & 35 & & $\sim N(2380,952)$ & & \\
16 & $\sim N(22000,8800)$ & $\sim N(1720,688)$ & 36 & & $\sim N(5600,2240)$ & & \\
17 & $\sim N(13000,5200)$ & $\sim N(2300,920)$ & 37 & & $\sim N(7800,3120)$ & & \\
18 & $\sim N(45000,18000)$ & $\sim N(1200,480)$ & 38 & & $\sim N(15630,6252)$ & & \\
19 & $\sim N(26000,10400)$ & $\sim N(4300,1720)$ & 39 & & $\sim N(9000,3600)$ & & \\
20 & $\sim N(17000,6800)$ & $\sim N(1200,480)$ & 40 & & $\sim N(7800,3120)$ & & \\
\hline
\end{tabular}




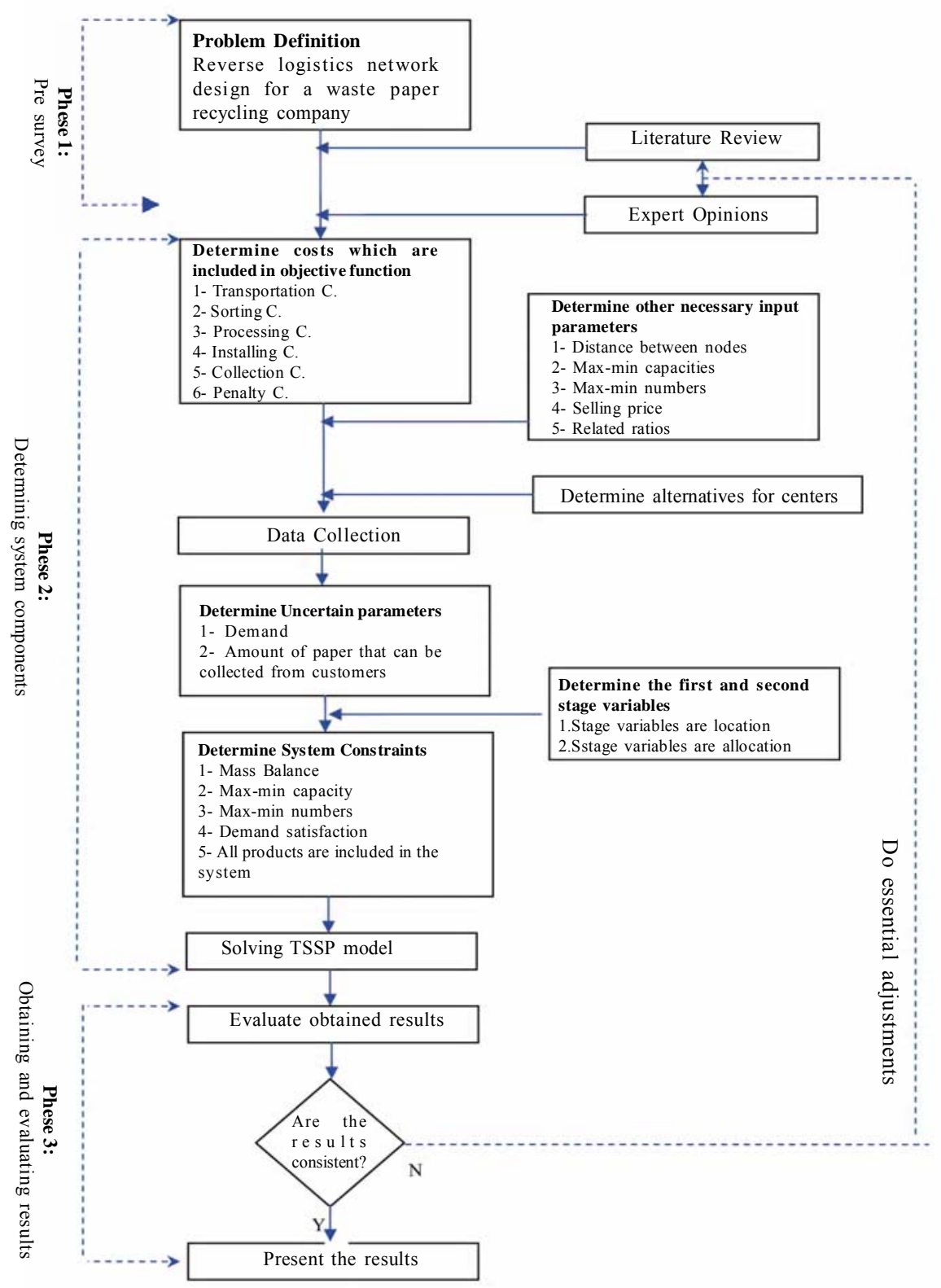

Fig. 2: The phases of the model

taken. In the second phase, parameters, variables, costs, constraints are determined and the model is solved. In the last phase model's results are obtained and if results are not valid, essential corrections are done. Eventually, results are represented.

The notation can be represented as follows:

Sets

$\mathrm{i}=$ Customer $\mathrm{j}=$ Collection center

$\mathrm{k}=$ Recycling center

$\mathrm{s}=$ Scenario

$j=1,2 \ldots \ldots, p$

$k=1,2, \ldots \ldots, q$

$s=1,2, \ldots \Omega$

Parameters

$a_{i s}=$ The number of products that can be collected from customer $i$ in scenario $s$

$B$ min $=$ Minimum capacity of collection center

$B m \alpha_{j}=$ Maximum capacity of collection center $j$

$F$ min = Minimum capacity of recycling center

$F m \alpha_{k}=$ Maximum capacity of recycling center $k$ 
$L_{\max }=$ Maximum number of collection centers

$J_{\text {max }}=$ Maximum number of recycling centers

$L_{\min }=$ Minimum number of collection centers

$J_{\text {min }}=$ Minimum number of recycling centers

$d_{i s}=$ Demand of product in customer $i$ in scenario $s$

$C_{j}=$ Cost of opening collection center $j$

$G_{k}=$ Cost of opening recycling center $k$

$K^{1}=$ Transportation cost between customer and recycling center (per ton and per $\mathrm{km}$ )

$K^{2}=$ Transportation cost between recycling center and customer (per ton and per $\mathrm{km}$ )

$K^{3}=$ Transportation cost between recycling center and waste center (per ton and per $\mathrm{km}$ )

$K^{4}=$ Transportation cost between customer and collection center (per ton and per $\mathrm{km}$ )

$K^{5}=$ Transportation cost between collection center and recycling center (per ton and per $\mathrm{km}$ )

$K^{6}=$ Transportation cost between collection center and waste center (per ton and per $\mathrm{km}$ )

$P=$ Collection cost from customer

$N_{1}=$ Loss cost for not collecting used product from customer

$S^{1}=$ Sorting cost in recycling center

$S^{2}=$ Sorting cost for collected product which is not disposed and is sorted with a higher cost in recycling center

$S^{3}=$ Sorting cost in collection center

$S^{4}=$ Sorting cost for collected product which is not disposed and is sorted with a higher cost in collection center

$V f=$ Processing cost for product which is produced from new raw material

$V r$ = Processing cost for product which is produced from recycled raw material

$q_{i k}^{1}=$ Distance from customer $i$ to recycling center $k$

$q_{k}^{2}=$ Distance from recycling center $k$ to waste center

$q_{i j}^{3}=$ Distance from customer $i$ to collection center $j$

$q_{j k}^{4}=$ Distance from collection center $j$ to recycling center $k$

$q_{j}^{5}=$ Distance from collection center $j$ to waste center

$\beta=$ Maximum percentage of uncollected product at customer

$\beta_{1}=$ Percentage of worse condition product in recycling center

$\beta_{2}=$ Percentage of worse condition product in collection center

$\alpha=$ Coefficient related to the capacity of recycling center of product which is produced from recycled raw material

$\operatorname{Pr}=$ Price of product

$V=$ Very large number

$p_{s}=$ Probability of scenario $s$

\section{Variables}

$x_{j}=1$ if collection center $j$ is opened 0 otherwise

$y_{k}=1$ if recycling center $k$ is opened 0 otherwise

$e_{k}=1$ if recycling center $k$ has sorting capability 0 otherwise

$O_{i s}=$ Amount of products which is not collected from customer $i$

$w_{i j s}=$ Amount of products which is transferred from customer $i$ to collection center $j$ in scenario $s$

$z f_{\text {kis }}=$ Amount of new product which is produced from new raw material and is transferred from recycling center $k$ to customer $i$ in scenario $s$

$Z r_{\text {kis }}=$ Amount of products which is produced from recycled raw material and is transferred from recycling center $k$ to customer $i$ in scenario $s$

$h_{i k s}=$ Amount of products which is transferred from customer $i$ to recycling center $k$ in scenario $s$

$u_{j k s}=$ Amount of products which is transferred from collection center $j$ to recycling center $k$ in scenario $s$

$f j_{j s}^{1}=$ Amount of products which is transferred from collection center $j$ to waste center

$f j_{j k s}^{2}=$ Amount of collected product which is not disposed and is sorted with a higher cost in collection center $\mathrm{j}$

$f k_{k s}^{1}=$ Amount of products which is transferred from recycling center $k$ to waste center

$f k_{\text {kis }}^{2}=$ Amount of collected product which is not disposed and is sorted with a higher cost in recycling center $k$

According to the model parameters, related data is obtained from a waste paper recycling company. For that reason, a detailed survey is conducted through the distribution of a comprehensive questionnaire for the managers and the related authorities in the company. Furthermore a large number of face-to-face interviews were held to develop solid information on the possible alternatives. During the interviews 17 possible locations are determined for recycling and collection centers in Istanbul, Turkey. The study is applied in 2009. Fig. 3 shows possible locations and customers. Also there are two waste centers in Istanbul which are in Eyup and Sile.

\section{Stochastic model formulation for reverse logistics} network design

The problem can be formulated as follows:

s.t

$\begin{array}{ll}y_{k} \geq e_{k} & \forall \quad k \\ h_{i k s} \leq V^{*} e_{k} & \forall \quad \mathrm{i}, k, s \\ o_{i s} \leq \beta^{*} a_{i s} & \forall \mathrm{i}, s\end{array}$

$\sum_{j=1}^{p} w_{i j s}+\sum_{k=1}^{q} h_{i k s}+o_{i s}=a_{i s} \quad \forall \quad i, s$

$\sum_{k=1}^{q} h_{i k s} \leq \sum_{j=1}^{p} w_{i j s} \quad \forall i, s$ 


$$
\begin{aligned}
& \sum_{k=1}^{q} u_{j k s}=\sum_{i=1}^{n} w_{i j s}-f j_{j s}^{1} \quad \forall j, s \\
& f j_{j s}^{2}+f j_{j s}^{1}=\sum_{i=1}^{n} \beta_{2} * w_{i j s} \quad \forall j, s \\
& \sum_{i=1}^{n} z r_{k i s}=\sum_{j=1}^{p} u_{j k s}+\sum_{i=1}^{n} h_{i k s}-f k_{k s}^{1} \quad \forall \quad k, s \\
& f k_{k s}^{2}+f k_{k s}^{1}=\sum_{i=1}^{n} \beta_{1} * h_{i k s} \quad \forall k, s \\
& \sum_{k=1}^{q}\left(z r_{k i s}+z f_{k i s} \text { Bmax }_{j} \quad \forall i, s\right. \\
& \sum_{i=1}^{n} w_{i j s} \leq x_{j} * \text { Bmin } \quad \forall j, s
\end{aligned}
$$

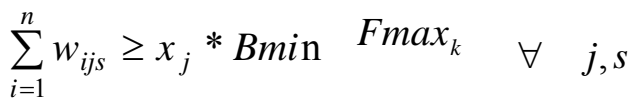

$$
\begin{aligned}
& \sum_{i=1}^{n}\left(z r_{k i s}+z f_{k i s}\right) \leq y_{k} * F F m i n \quad \forall \quad k, s \\
& \sum_{i=1}^{n}\left(z r_{k i s}+z f_{k i s} \text { Fmax }_{k}^{*} \text { Fmin } \quad \forall \quad k, s\right. \\
& \sum_{i=1}^{n} z r_{k i s} \leq \alpha * F_{m a F m a x} \quad \forall \quad k, s \\
& \sum_{i=1}^{n} z f_{k i s} \leq(1-\alpha) * F \max _{k} \quad \forall \quad k, s \\
& L_{\min } \leq \sum_{j=1}^{p} x_{j} \\
& L_{\max } \geq \sum_{j=1}^{p} x_{j} \\
& J_{\text {min }} \leq \sum_{k=1}^{q} y_{k} \\
& J_{\text {max }} \geq \sum_{k=1}^{q} y_{k}
\end{aligned}
$$

$$
\begin{aligned}
& \max _{s=1}^{\Omega} p_{s} *\left[\sum_{k=1}^{q} \sum_{i=1}^{n} \operatorname{Pr} *\left(z r_{k i s}+z f_{k i s}\right)-\sum_{i=1}^{n} N^{*} o_{i s}-\right. \\
& \sum_{i=1}^{n} \sum_{k=1}^{q} K^{1} * q_{i k}^{1} * h_{i k s}-\sum_{k=1}^{q} \sum_{i=1}^{n} K^{2} * q_{i k}^{1} *\left(z r_{k i s}+z f_{k i s}\right)- \\
& \sum_{k=1}^{q} K^{3} * q_{k}^{2} * f k_{k s}^{1}-\sum_{i=1}^{n} \sum_{j=1}^{p} K^{4} * q_{i j}^{3} * w_{i j s}- \\
& \sum_{j=1}^{p} \sum_{k=1}^{q} K^{5} * q_{j k}^{4} * u_{j k s}-\sum_{j=1}^{p} K^{6} * q_{j}^{5} * f j_{j s}^{1}-\sum_{i=1}^{n} \sum_{j=1}^{p} \sum_{k=1}^{q} P * \\
& \left(w_{i j s}+h_{i k s}\right)-\sum_{i=1}^{n} \sum_{k=1}^{q} S^{1} *\left(h_{i k s}-f k_{k s}^{2}\right) \\
& -\sum_{k=1}^{q} S^{2} * f k_{k s}^{2}-\sum_{i=1}^{n} \sum_{j=1}^{p} S^{3} *\left(w_{i j s}-f j_{j s}^{2}\right)-\sum_{j=1}^{p} S^{4} * f j_{j s}^{2}- \\
& \left.\sum_{k=1}^{q} \sum_{i=1}^{n} V r^{*} z r_{k i s}-\sum_{k=1}^{q} \sum_{i=1}^{n} V f * z f_{k i s}\right] \\
& -\sum_{j=1}^{p} C_{j} * x_{j}-\sum_{k=1}^{q} G_{k} * y_{k} \\
& 0 \leq O_{i s}, w_{i j s}, z r_{k i s}, z f_{k i s}, u_{j k s}, \\
& h_{i k s}, f j_{j s}^{1}, f j_{j k s}^{2}, f k_{k s}^{1}, f k_{k i s}^{2} x_{j}, y_{k}, e_{k} \in\{0,1\}(26)
\end{aligned}
$$

The objective function tries to maximize the profit consisting of revenue from products minus overall costs. The first term is revenue, the second term is penalty cost for not collecting products from customers, the third, the fourth, the fifth, the sixth, the seventh and the eighth terms are the transportation costs from customers to recycling center, from recycling center to customers, from recycling center to waste center, from customers to collection center, from collection center to recycling center, from collection center to waste center, respectively. The ninth term is the collection cost from customer, the tenth and the eleventh terms are sorting costs in recycling center, the twelfth and the thirteen terms are the sorting costs in collection center, the fourteenth and the fifteenth terms are the processing costs and the last two terms are the installation costs for collection center and recycling center, respectively. Constraint (6) guarantees that sorting capability can only be assigned to recycling center which is opened. Constraint (7) ensures that all collected products have to be sorted in recycling 
center. Constraint (8) limits the amount of uncollected products. Constraint (9) is flow conservation constraint. Constraint (10) ensures that the amount of products that are transferred to collection center are greater than the amount of products that are transferred to recycling center. Constraint (11) ensures that the outgoing flow of products can not exceed the incoming flow in collection center. Constraint (12) guarantees that all products in bad condition in collection center are transferred to waste center or are sorted with a higher cost. Constraint (13) is mass balance constraint in recycling center. Constraint (14) guarantees that all products in bad condition in recycling center are transferred to landfill or are sorted with a higher cost. Constraint (15) is demand satisfaction constraint. Constraints (16) and (17) are the maximum and minimum capacity limitations for collection centers and constraints (18) and (19) are the maximum and minimum capacity limitations for recycling center, respectively. Constraint (20) assigns a portion of capacity for products which are produced from recycled raw materials and constraint (21) assigns a portion of capacity for products which are produced from new raw materials. Constraints (22) and (23) ensure maximum and minimum numbers for opening collection center and constraints (24) and (25) ensure maximum and minimum numbers for opening recycling center, respectively. Constraint (26) specifies the integrality of the location variables and non-negativity for flow variables.

\section{RESULTS AND DISCUSSION}

Both deterministic and stochastic models are solved in Windows XP Centrino $1.66 \mathrm{GHz}$ and 512 MB of memory. All models are mixed-integer programming models and solved by commercial software GAMS 21.6/CPLEX 6.0. The objective functions, CPU times, number of continuous and integer variables, iterations and constraints are summarized in Table 3 . The deterministic value which is mentioned here is the mean value of forty deterministic models which use the values of every scenario. As can be seen from the Table 3, the mean objective value of forty deterministic models is higher than the stochastic model's objective value. Also when this stochastic objective value is compared with forty deterministic models' objective values, it has still lower objective value than the most of these forty objective values. This lower objective value is because of selecting the optimal and economical locations for recycling and collection center. Therefore, it can be concluded that the stochastic model's results propose more economical and compromised solution. In the stochastic model's result, the fifth location is chosen for the recycling center and the sixth and the fifteenth locations are chosen for the collection center. These choices are meaningful because the sixth location is situated in the Anatolian side of Istanbul and the fifteenth location is situated in the European side of Istanbul. Also the sixth and the fifteenth locations are nearer to the industrial zones, this will cause an decrease in transportation cost and response time. Another good aspect of being close to industrial zones is that these places are far from residential area. This will eliminate bad social effects. Hence, optimal locations are chosen for collection centers. These results reflect that all customers that are located in Anatolian and European sides can be served completely. Besides, compared to the other locations all the selected locations (mostly the fifth) are located in an area where high level of industrial population exists.

It is found in the stochastic model's results that all customers' demands are satisfied by the new product produced from both new and recycled raw material in all scenarios as shown in Fig. 4. The graphic shows in what percentage of the examined scenarios the customers' demands are satisfied by products which are produced using new or recycled raw materials. For example in $65 \%$ of the scenarios, customer 1 's demand is satisfied by products produced using recycled raw materials while in $38 \%$ customer 1 's demand is satisfied by products produced using new raw materials. Thereby; in $3 \%$ of the scenarios, customer 1's demand is satisfied by products produced using both new and recycled raw materials. On the other hand; in $80 \%$ of the scenarios, customer 2's demand is satisfied by products produced using recycled raw materials while in $20 \%$, customer 2's demand is satisfied by products produced using new raw materials. Hence, some customers are served by products produced using either new or recycled raw materials but some customers are served by products produced using both new and recycled raw materials. As can be seen 
S. Soner Kara; S. Onut

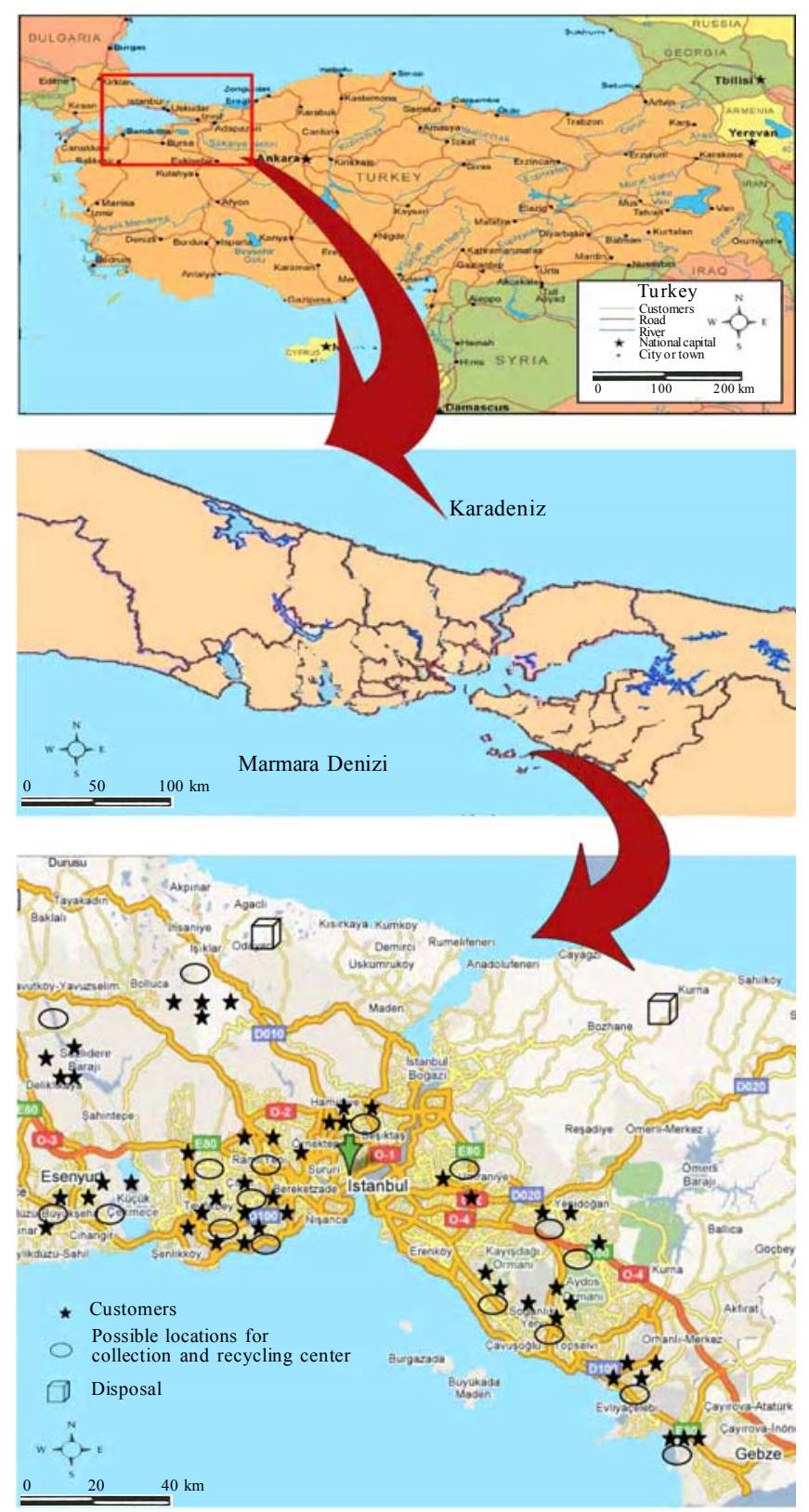

Fig. 3: The graph of the recycling network

Table 3: Summary of the models

\begin{tabular}{lrr}
\hline & Deterministic model & Stochastic model \\
\hline Objective function & $175,990,111.1 \mathrm{TL}$ & $173,739,507.8 \mathrm{YTL}$ \\
CPU time & 11.6 sec. & $75,817.4$ \\
Number of iterations & 32,665 & $5,515,170$ \\
Number of continuous variables & 3,859 & 152,332 \\
Number of integer variables & 51 & 51 \\
Number of constraints & 1,242 & 488,22 \\
\hline
\end{tabular}


from the graph, ten customers have their demands satisfied with products produced using both new and recycled raw materials while twenty of them have their demands satisfied with products produced using either new or recycled raw materials.

Another investigation is done for allocation of the collected products from customers. This is explained in Fig. 5. The graphic reveals the fraction of the collected products from customers that is served by each center. For example, the collected products from customer 1 is totally brought to collection center 6 , while the collected products from customer 2 is totally brought to collection center 15 whereas half of the collected products from customer 3 is brought to collection center 6 and half of its products is directly brought to recycling center 5 . Thus, some of the collected products from customers are brought only to collection centers but others are brought to both collection centers and recycling center. As can be seen from the graph the collected products from only three customers are brought to both collection centers and recycling center. All results indicate that the twostage stochastic model is suitable for recycling network design.

\section{CONCLUSION}

Some activities of the reverse supply chain, like the recycling of the products, have been put into practice for years, hence the existing growth in utilization exhibits efficient results. These are; reducing resources, waste and environmental pollution. These efficient results motivate producers to pay attention to these issues. Combined with economical benefits, reverse supply chain activity is the best strategy for producers. The design of supply chain networks is a difficult task because of the complexity. Moreover in reverse logistics the decisions are harder to make than traditional supply

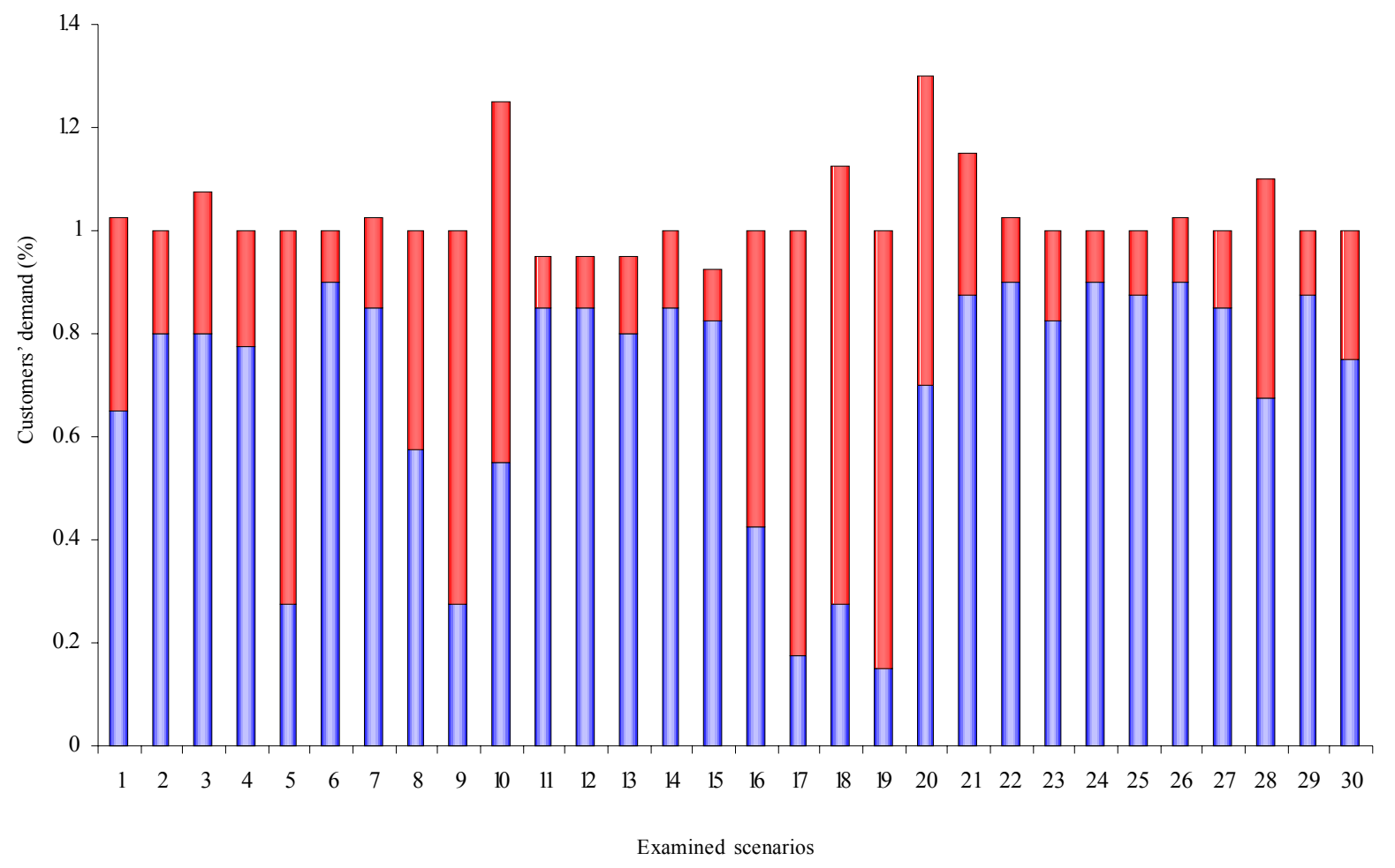

$\square$ Cus tomers' demands are satis fied bypapaer produced from recycled rawmaterial $\square$ Customers' demands are satis fied by papaer produced from newrawmaterial

Fig. 4: The ratio of customers' demand satisfaction in stochastic result 


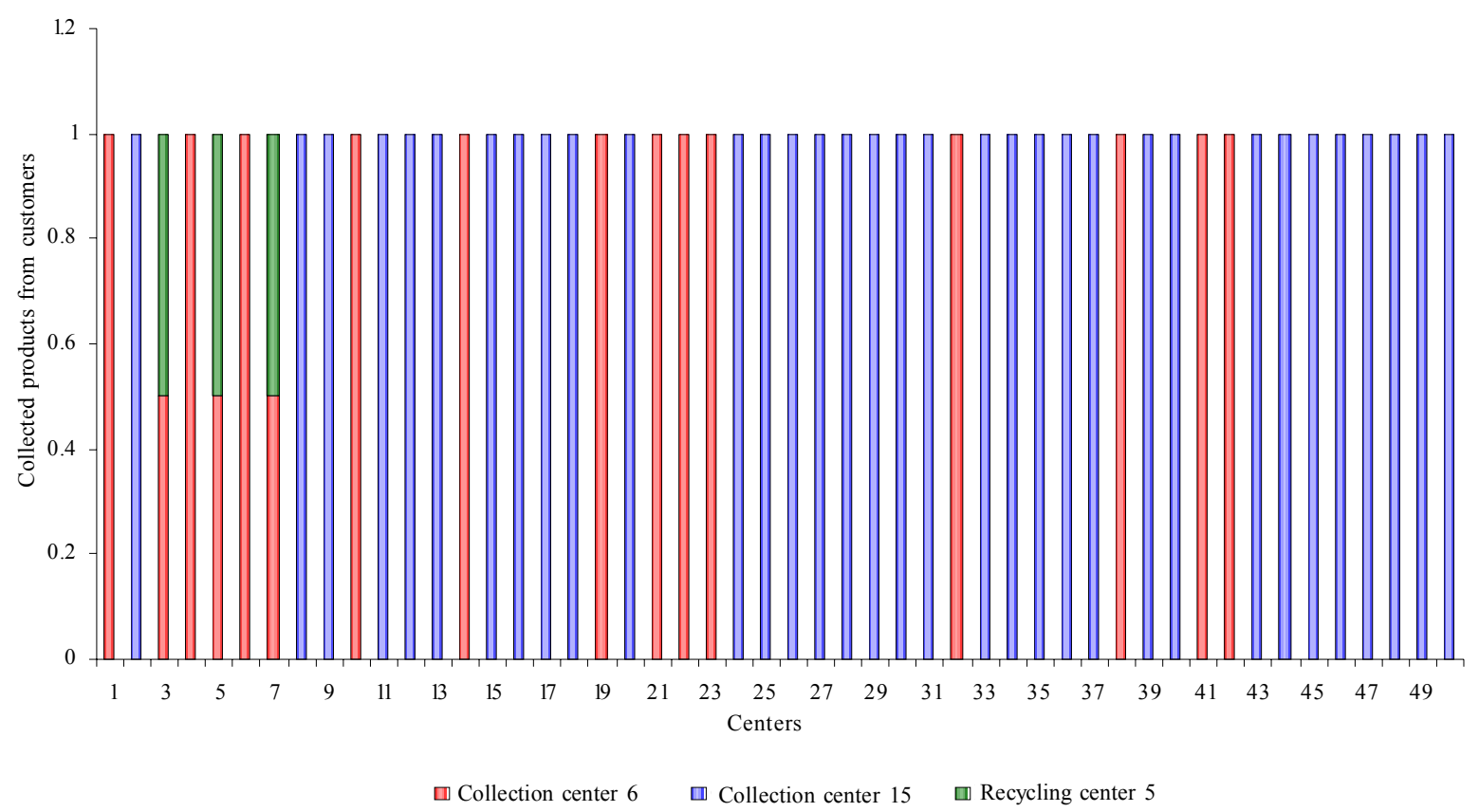

Fig. 5: The ratio of customers' return allocation in stochastic result

chains. The location/allocation decisions play an important role in the success of design of infrastructure of the network. Uncertainty is one of the characteristics of the real world. The methods that cope with uncertainty help researchers get realistic results. Stochastic programming is a sufficient approach in dealing with uncertainty. In the real world, factors are not always certain, however in deterministic programming, factors are assumed as certain. But stochastic programming is a programming method that deals with uncertainty. In this paper, as a real world case study of paper recycling, a reverse supply chain network design problem is presented under uncertainty. The model takes into account a number of alternative scenarios for demand and the amount of products that can be collected from customers. These solutions are progressively less sensitive to realizations of the data in a scenario set. The objective of this study is to analyze stochastic programming techniques for reverse supply network design problems. Compared with the deterministic model, stochastic model can corporate uncertain information. This study is suitable for recycling/ manufacturing systems in reverse supply chain. The model includes some constraints that exist in the literature but additional ones are proposed which are not related to previous models. Also different variables are included in the model. This model can be extended in different aspects in order to deal with complex decisional issues more accurately. For further research a more detailed model can be presented. Also the number of alternatives and scenarios can be increased. Lastly, heuristics and decomposition methods can be combined with the method to decrease running times.

\section{ACKNOWLEDGMENTS}

The author is partially supported by the TUBITAKTurkish Scientific and Technologic Research Association and wish to thank its financial support.

\section{REFERENCES}

Abdel-Ghani, N. T.; Elchaghaby, G. A., (2007). Influence of operating conditions on the removal of $\mathrm{Cu}, \mathrm{Zn}, \mathrm{Cd}$ and $\mathrm{Pb}$ ions from wastewater by adsorption. Int. J. Environ. Sci. Tech., 4 (4), 451-456 (6 pages).

Abdel-Ghani, N. T.; Hegazy, A. K.; El-Chaghaby, G. A., (2009). Typha domingensis leaf powder for decontamination of aluminium, iron, zinc and lead: Biosorption kinetics and equilibrium modeling. Int. J. Environ. Sci. Tech., 6 (2), 243-248 (6 pages). 
Alumur, S.; Kara,, B. Y., (2007). A new model for the hazardous waste location-routing problem. Comput. Operat. Res., 34 (5), 1406-1423 (18 pages).

Bandyopadhyay, G.; Chattopadhyay, S., (2007). Single hidden layer artificial neural network models versus multiple linear regression model in forecasting the time series of total ozone. Int. J. Environ. Sci. Tech., 4 (1), 141-150 (10 pages)

Barros, A. I.; Dekker, R.; Scholten, V., (1998). A two-level network for recycling sand: A case study. Europ. J. Operat Res., 110 (2) , 199-214 (16 pages).

Beamon, B. M.; Fernandes, C., (2004). Supply-chain network configuration for product recovery. Product. Plan. Control., 15 (3), 270-281 (12 pages).

Birge, J. R.; Louveaux, F., (1997). Introduction to Stochastic Programming, Berlin: Springer-Verlag.

Blanc, H. M.; Fleuren, H. A.; Krikke, H. R., (2004). Redesign of a recycling system for LPG-tanks. OR Spectrum., 26 (2), 283-304 (22 pages).

Chien, M. K.; Shih, L. H., (2007). An empirical study of the implementation of green supply chain management practices in the electrical and electronic industry and their relation to organizational performances. Int. J. Environ. Sci. Tech., 4 (3), 383-394 (12 pages).

Chouinard, M.; D'Amoursa, S.; Ait-Kadi, D., (2008). A stochastic programming approach for designing supply loops. Int. J. Product. Econom., 113 (2), 657-677 (21 pages).

Chowdhury, R. K; Rahman, R., (2008). Multicriteria decision analysis in water resources management: the malnichara channel improvement. Int. J. Environ. Sci. Tech., 5 (2), 195-204 (10 pages).

Farzaneh, H., Saboohi, Y., (2007). Evaluation of the optimal performance of passenger vehicle by integrated energyenvironment-economic modeling. Int. J. Environ. Sci. Tech., 4 (2), 189-196 (8 pages).

Hu, T. L.; Sheu, J. B.; Huang, K. H., (2002). A reverse logistics cost minimization model for the treatment of hazardous wastes. Transport. Res. Part E., 38 (6), 457473 (17 pages).

Jalili Ghazi Zade, M.; Noori, R., (2008). Prediction of municipal solid waste generation by use of artificial neural network: A case study of Mashhad. Int. J. Environ. Res., 2 (1), 13-22 (10 pages).

Jayaraman, V.; Patterson, R. A.; Rolland, E., (2003). The design of reverse distribution networks: Models and solution procedures. Europ. J. Operat. Res., 150 (1), 128 149 (22 pages).

Ko, H. J.; Evans, G. W., (2007). A genetic algorithm-based heuristic for the dynamic integrated forward/reverse logistics network for 3PLs. Comput. Operat. Res., 34 (2), 346-366 (21 pages).

Krikke, H. R.; Harten, A. V.; Schuur, P. C., (1999). Business case Oce: Reverse logistic network re-design for copiers. OR Spectrum., 21 (3), 381-409 (29 pages).

Krikke, H.; Bloemhof-Ruwaard, J.; Wassenhove, L. N. V., (2003). Concurrent product and closed-loop supply chain design with an application to refrigerators. Int. J. Product. Rese., 41 (16), 3689-3719 (31 pages).
Lee, D. H.; Dong, M., (2008). A heuristic approach to logistics network design for end-of-lease computer products recovery. Transportation Research Part E., 44 (3), 455-474 (20 pages).

Lieckens, K.; Vandaele, N., (2007). Reverse logistics network design with stochastic lead times. Computers and Operations Research., 34 (2), 395-416 (22 pages).

Lin, K. H.; Shih, L. H.; Lee, S. C., (2010). Optimization of product line design for environmentally conscious technologies in notebook industry. Int. J. Environ. Sci. Tech., 7 (3), 473-484 (12 pages).

Listes, O., (2007). A generic stochastic model for supplyand-return network design. Computers and Operations Research., 34 (2), 417-442 (26 pages).

Listes, O.; Dekker, R., (2005). A stochastic approach to a case study for product recovery network design. European Journal of Operational Research., 160 (1), 268-287 (20 pages).

Lu, Z.; Bostel, N., (2007). A facility location model for logistics systems including reverse flows: The case of remanufacturing activities. Comput. Operat. Res., 34 (2), 299-323 (25 pages).

Maqsood, I.; Huang, G. H., (2003). A two-stage interval stochastic programming model for waste management under uncertainty. J. Air Waste Manag. Associat., 53 (5), 540-552 (13 pages).

Min, H.; Ko, H. J., (2008). The dynamic design of a reverse logistics network from the perspective of third-party logistics service providers. Int. J. Product. Econom., 113 (1), 176-192 (17 pages).

Min, H.; Ko, H. J.; Ko, C. S., (2006). A genetic algorithm approach to developing the multi-echelon reverse logistics network for product returns. Omega, 34 (1), 56-69 (14 pages).

Nema, A. K.; Gupta, S. K., (1999). Optimization of regional hazardous waste management systems: An improved formulation. Waste Manag., 19 (7-8), 441-451 (11 pages).

Panjeshahi, M. H.; Ataei, A., (2008). Application of an environmentally optimum cooling water system design in water and energy conservation. Int. J. Environ. Sci. Tech., 5 (2), 251-262 (12 pages).

Pati, R. K.; Vrat, P.; Kumar, P., (2008). A goal programming model for paper recycling system. Omega., 36 (3), 405417 (13 pages).

Salema, M. I. G.; Barbosa-Povoa, A. P.; Novais, A. Q., (2006). A warehouse-based design model for reverse logistics. J. Operat. Res. Soc., 57 (6), 615-629 (15 pages).

Salema, M. I. G.; Barbosa-Povoa, A. P.; Novais, A. Q., (2007). An optimization model for the design of a capacitated multi-product reverse logistics network with uncertainty. Europ. J. Operat. Res., 179 (3), 1063-1077 (15 pages).

Sheu, J. B., (2007). A coordinated reverse logistics system for regional management of multi-source hazardous wastes. Comput. Operat. Res., 34 (5), 1442-1462 (21 pages).

Shih, L., (2001). Reverse logistics system planning for recycling electrical appliances and computers in Taiwan. Resour. Conserv. Recycl., 32 (1), 55-72 (18 pages).

Spengler, T.; Püchert, H.; Penkuhn, T.; Rentz, O., (1997). Environmental integrated production and recycling 
management. Europ. J. Operat. Res., 97 (2), 308-326 (19 pages).

Tuzkaya, G.; Gülsün, B., (2008). Evaluating centralized return centers in a reverse logistics network: An integrated fuzzy multi-criteria decision approach. Int. J. Environ.
Sci. Tech., 5 (3), 339-352 (14 pages).

Tuzkaya; G. Ozgen, A., Ozgen, D., Tuzkaya, U. R., (2009).

Environmental performance evaluation of suppliers: A hybrid fuzzy multi-criteria decision approach. Int. J. Environ. Sci. Tech., 6 (3), 477-490 (14 pages).

AUTHOR (S) BIOSKETCHES

Soner Kara, S., M.Sc., Ph.D. research assistant, Department of Industrial Engineering, Yildiz Technical University, Yildiz, Turkey. Email: ssoner@yildiz.edu.tr

Onut, S., Associate Professor, Department of Industrial Engineering, Yildiz Technical University, Yildiz, Turkey. Email: onut@yildiz.edu.tr

How to cite this article: (Harvard style)

Soner Kara, S.; Onut, S., (2010). A stochastic optimization approach for paper recycling reverse logistics network design under uncertainty. Int. J. Environ. Sci. Tech., 7 (4), 717-730. 